\title{
"Mientras LaS GÁrgolas NOS MIRAN". UN SITIO ARQUEOLÓGICO URBANO ¿Y RELIGIOSO? en la ciudad de LuJán. Provincia de Buenos Aires
}

\author{
Mariano Ramos, Alejandra Raies y Matías Warr*
}

\begin{abstract}
Resumen
En los meses de noviembre de 2015 y en mayo de 2016 realizamos investigaciones de Arqueología Urbana en un sitio ubicado en la ciudad de Luján. El predio se sitúa entre las calles San Martín y 9 de Julio, frente a la basílica y dentro del casco histórico. Los estudios se llevaron a cabo por solicitud de la Iglesia representada por el sacerdote Sergio Gómez Tey y por intermedio del arquitecto Raúl Vilieri, Secretario de Producción, Turismo y Cultura de la Municipalidad de Luján. El objetivo principal fue el de ubicar los posibles vestigios de la primera capilla de Luján, llamada de Montalvo. La misma tuvo existencia entre los siglos XVII y XVIII y sería la sede original que albergó la Imagen de la Virgen con su cuidador, el conocido como "Negrito Manuel".

En esta presentación exponemos los resultados obtenidos luego de los trabajos de campo en el sitio. Estos fueron desarrollados en carácter de Arqueología de rescate ya que el lugar estaba afectado por la instalación de nuevas obras. Asimismo damos a conocer la información resultante de los estudios de gabinete realizados.
\end{abstract}

Palabras clave: Arqueología Urbana, Arqueología de rescate, Capilla Montalvo, Luján, ¿Sitio Religioso?

\begin{abstract}
On November 2015 and May 2016 we conducted research on Urban Archeology at a site located in the city of Luján. The property is located between San Martín and 9 de Julio streets, in front of the basilica and inside the historic center. The studies were carried out at the request of the Church requested by the priest Sergio Gómez Tey and through the architect Raúl Vilieri, Secretary of Production, Tourism and Culture of the Municipality of Luján. The main objective was to locate the possible vestiges of the first chapel of Luján, called de Montalvo. The same had existence between the seventeenth and eighteenth centuries and would be the original seat that housed the Image of the Virgin with his caretaker, known as "Negrito Manuel."

In this presentation we present the results obtained after the field work on the site. These were developed in character of rescue archeology since the place was affected by the installation of new works. We also announce the information resulting from the cabinet studies carried out.

Keywords: Urban Archeology, Rescue Archeology, Montalvo Chapel, Luján, Religious Site?
\end{abstract}

* Programa de Arqueología Histórica y Estudios Pluridisciplinarios. Universidad Nacional De Luján. 


\section{Introducción}

En este trabajo se presentan las actividades llevadas a cabo en el trabajo de campo desarrollado en noviembre 2015 y mayo de 2016 en el terreno ubicado entre las calles San Martín y 9 de Julio de la ciudad de Luján, donde se supone se ubicarían los restos de la Capilla de Montalvo y la Virgen, de la que fuera su cuidador el famoso "Negrito Manuel".

El objetivo es evaluar si en dicho lugar estuvo la antigua Capilla de Montalvo que tuvo existencia entre los siglos XVII y XVIII. El terreno en donde se llevaron a cabo las tareas arqueológicas, corresponde al predio de nomenclatura catastral Circunscripción I, Sección A, Manzana 53, Parcela 2, aledaño a la Basílica Nacional "Nuestra Señora de Luján”, ciudad de Luján.

La primer Capilla llamada de Montalvo habría sido terminada en 1685 y sería la sede original que albergó la Imagen de la Virgen con su cuidador, el conocido como "Negrito Manuel". Los estudios se llevaron a cabo por solicitud de la Iglesia representada por el sacerdote Sergio Gómez Tey y por intermedio del arquitecto Raúl Vilieri, Secretario de Producción, Turismo y Cultura de la Municipalidad de Luján y del Señor Ronaldo Rossi Montero, dueño de la propiedad, respectivamente.

\section{Antecedentes}

Entre los antecedentes con los que se cuenta para un mejor conocimiento de la Historia religiosa de la Época Colonial y del Periodo de Independencia Nacional para el área de Luján, se destaca el trabajo clásico del Padre Salvaire (1885), como el de Juan Presas (1974). Recientemente han realizado aportes las historiadoras Mónica Fernández (1997); María Elena Barral (entre otros trabajos 2004 y 2013); Patricia Fogelman quien ha realizado varias contribuciones a la temática $(1999 ; 2000 ; 2002$ y 2006). También el historiador Binetti ha realizado un aporte reciente (2015 MS).

En aspectos particulares de los orígenes y la vida en el pago, pueblo y luego ciudad de Luján, se encuentran las contribuciones de Dorronzoro (un clásico de 1950); Marquiegui (1990); Cortabarria (2009). Todos estos y otros varios trabajos publicados representan valiosos antecedentes para un mejor conocimiento de los temas que mencionamos. Sin embargo, nunca se había realizado una investigación arqueológica en el área de influencia de la Basílica que se refiriera a los antecedentes de la primera fundación de la mítica Capilla Montalvo que albergara durante el siglo XVII y XVIII a la Virgen y al famoso Negrito Manuel.

Si bien hemos investigado en distintos temas de la denominada Arqueología histórica (Ramos 2000 y 2003) y en distintos sitios arqueológicos, incluso en la ciudad de Luján como las Casas de Florentino Ameghino (por ejemplo Ramos et al., 2007 y 2014; Helfer et al., 2011), este es el primer estudio desde perspectivas arqueológicas que se realiza con la finalidad de buscar y detectar los indicios de aquella temática tan importante para la vida religiosa de Luján y de la Argentina: la Capilla Montalvo y sus orígenes.

\section{EI sitio arqueológico}

El predio se sitúa entre las calles San Martín y 9 de Julio, frente a la basílica y dentro del casco histórico. Nomenclatura catastral Circunscripción I, Sección A, Manzana 53, Parcela 2, aledaño a la Basílica Nacional "Nuestra Señora de Luján”, ciudad de Luján (Figura 1). 

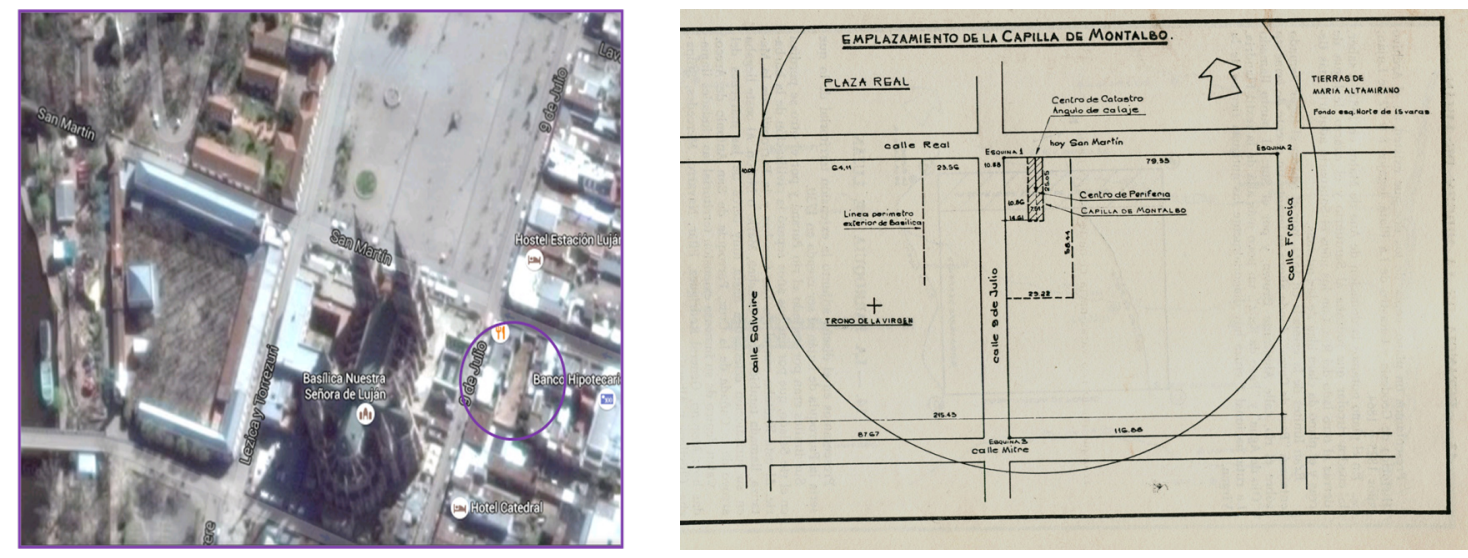

Figura 1.Izq. Foto satelital del área de la basílica de Luján. En violeta el terreno en forma de L en donde se ubicarían los restos de la Capilla Montalvo de 1685. Der. Plano desarrollado por Presas (1974, p. 453).

\section{Trabajo de campo}

Las tareas arqueológicas desarrolladas en el predio aledaño a la Basílica Nacional "Nuestra Señora de Luján", fueron las siguientes (Figura 2):

1. Limpieza parcial del terreno (retiro o corrimiento de escombros, montículos de tierra, hierros y otro material que se ubicara en el lugar y que impedía el estudio);

2. Inspección visual y evaluación del área en estudio;

3. Apertura de 3 trincheras de entre 0,50 y $0,60 \mathrm{~m}$ de ancho por $4 \mathrm{~m}$ de largo con una profundidad de $2 \mathrm{~m}$;

4. Realización de 1 sondeo de 1,00 por $1,00 \mathrm{~m}$ de lado por $1,50 \mathrm{~m}$ de profundidad y de 3 sondeos en la parte inferior de las paredes de la medianera vecina opuesta a la ubicación de la Basílica de Luján;

5. Ampliación de la extensión de las trincheras I y III para que alcanzaran la pared próxima a la calle 9 de Julio. Apertura de un corte perpendicular a la trinchera II de entre 0,50 y 0,60 m de ancho por $4 \mathrm{~m}$ de largo con una profundidad de $2 \mathrm{~m}$;

4. Excavación parcial de los rellenos de la cisterna, la que anteriormente había sido considerada como un aljibe;

5. Evaluación de los posibles restos hallados en las trincheras y cisterna;

6. Todas las tareas desarrolladas se registraron en libretas de campo, dibujos y fotos. 

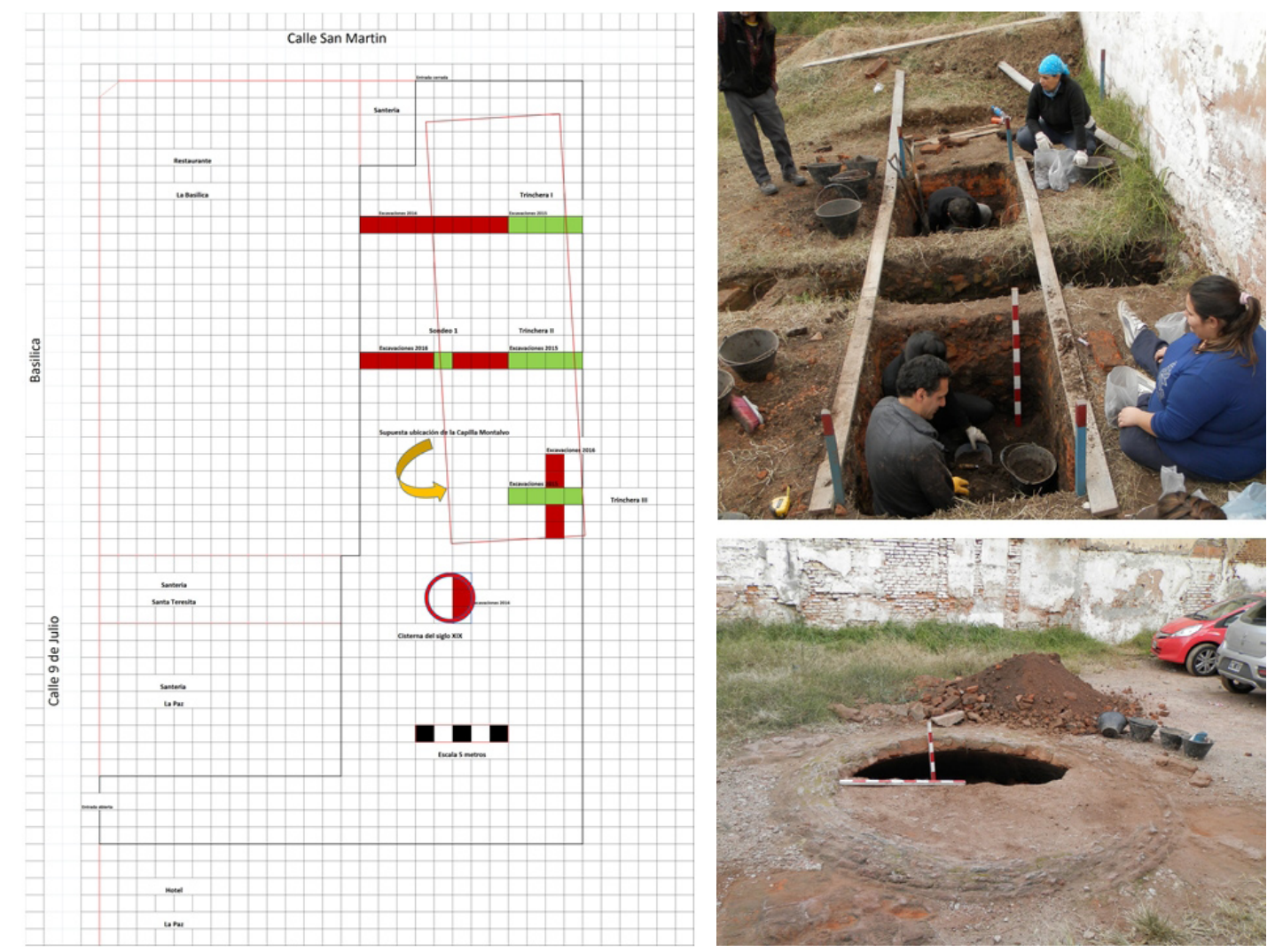

Figura 2. Izq. Plano del área en donde se ubica el terreno. Se indican las trincheras (I, II y III), el sondeo 1 realizados en noviembre de 2015, trincheras y cisterna excavadas en 2016 y la hipotética ubicación de la Capilla Montalvo según Federico Suárez y Jesús Binetti. Der. Fotos de la excavación de trinchera y cisterna

\section{Registro Arqueológico}

Los materiales arqueológicos hallados en las excavaciones fueron trasladados al Laboratorio del ProArHEP, ubicado en la Sede Capital de UNLu (Ecuador 871, primer piso). En el Laboratorio fueron acondicionados para su estudio los materiales arqueológicos hallados en las excavaciones de 2015 y 2016. Se realizaron los siguientes pasos: 1. Apertura de las bolsas con el contenido y sus correspondientes rótulos identificatorios según el registro de campo; 2. Lavado del material según el conjunto al que corresponden (óseo, metal, vidrio, etc.); 3. Primer fotografiado de las piezas; 4. Estudio de cada uno de los objetos arqueológicos. 5. cuantificación y confeccionado de tablas y gráficos para su interpretación según criterio morfológico funcional y materialidad (Figura 3). 

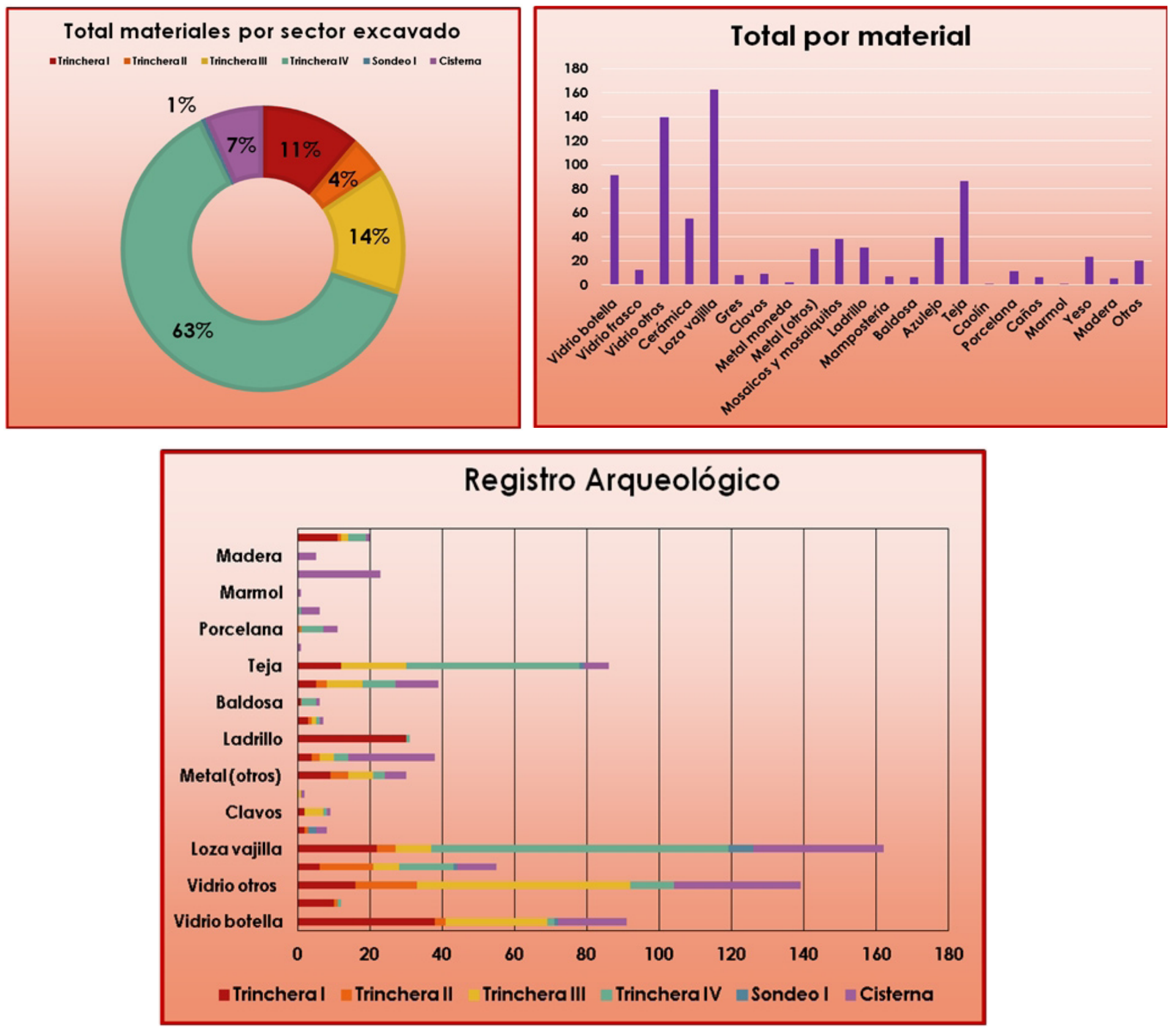

Figura 3. Arriba izq. Gráfico según porcentaje total de acuerdo a la unidad de procedencia. Arriba der. Gráfico según tipo de material. Abajo. Gráfico material según unidad de excavación

\section{Interpretación del registro}

Para hacer una interpretación de los hallazgos y establecer la secuencia cronológica de la ocupación del terreno, tenemos estas posibilidades y perspectivas:

1. Si bien se hallaron restos de paredes, pisos, albañales y otros restos de estructuras de construcción durante las excavaciones de noviembre de 2015, y luego las realizadas en mayo de 2016, no se hallaron los restos de las paredes u otras estructuras de la denominada Capilla Montalvo de 1685.

2. La mayoría de los restos de estructuras constructivas hallados pertenecen a la casa de la 
segunda mitad del siglo XIX habitada por la familia de Rossi Montero, (Ronaldo Rossi Montero comunicación personal, 2016). Asimismo, existen otros restos de paredes y pisos de construcciones anteriores a esa vivienda. Algunos restos pueden alcanzar, cronológicamente, las últimas décadas del Periodo Colonial.

3. Los hallazgos de objetos del registro arqueológico corresponden a los siglos XX, XIX y posiblemente al XVIII (alguno, que se debe confirmar, podría ser del siglo XVII).

4. Sobre la base de lo expresado, hacemos una síntesis de los hallazgos y su interpretación con algún detalle que brinde mayor precisión.

Así tenemos que (Figura 4):

1. Los fragmentos de loza, cerámica y vidrio son restos de vajilla y botellas de bebidas alcohólicas (vino tinto) del siglo XIX.

2. La vasija ensamblada, hallada en 2015 , es de forma globular y presenta dos asas con borde evertido; es de factura irregular y rústica; se encuentra cubierta por hollín por lo que fue empleada para cocinar alimentos al fuego directo durante gran parte de su vida útil hasta su posterior fractura y abandono. Es una vasija que puede ser colonial.

3. Las dos pequeñas vasijas de factura similar pero sin pueden ser recipientes cerámicos rústicos del siglo XVIII o anteriores. Su factura es una combinación de formas y técnicas europeo-criollas con indígenas.

4. Los fragmentos de teja como los que se hallaron en la Trinchera II corresponden a una cerámica de terminación rústica. Se trataría de tejas "musleras", preparadas en los muslos de las piernas de los artesanos que las confeccionaban. Su pasta es homogénea pero su espesor es irregular como sus terminaciones. Serían hallazgos anteriores a las ocupaciones de la antigua casa construida durante la segunda mitad del siglo XIX. Incluso es muy probable que sean restos de tejas coloniales del siglo XVIII o quizás, anteriores.

En cuanto a las estructuras constructivas tenemos lo siguiente:

5. Los tipos de ladrillos hallados en las excavaciones de las Trincheras I, II, III y IV corresponden, por sus dimensiones (por ejemplo, 0,42 x 0,21 x 0,05 m), a objetos de la segunda mitad del siglo XIX y principios del XX (los de 0,30 x 0,15 x 0,05 m). Son conocidos por los estudios que hiciera Schávelzon (1991) en los sitios de la Ciudad de Buenos Aires. La fabricación de ladrillos, tejas y otros elementos de construcción se remonta a principios del 1600; los primeros se llamaban "de barro" y las construcciones eran denominadas como "de tierra cruda" (Schávelzon ,1991). Durante la segunda mitad del siglo XVII ya hacía algunas décadas que se fabricaban en el país por lo que sería factible que la Capilla Montalvo estuviera hecha con algún tipo de ladrillo, quizás de forma cuadrangular.

6. Los albañales hallados (puede ser el mismo en su extensión, cortado por las trincheras), corresponden al siglo XIX. El tipo de ladrillo y la base de baldosas rústicas de cerámica francesa, así lo testimonian.

7. Los tipos de construcciones halladas (restos de paredes, patios, veredas, albañales, etc.) y las características del material empleado en esas construcciones sugieren que fueron confeccionadas durante los siglos XIX y XX. Sin embargo existen materiales, como los restos de tejas, que corresponderían a periodos anteriores, posiblemente al siglo XVIII o quizás antes. Algunos ladrillos cuyas medidas oscilan entre los 0,42 y 0,43 $\mathrm{m}$ de largo por 0,22 o $0,23 \mathrm{~m}$ de ancho y alrededor de $0,05 \mathrm{~m}$ de espesor pueden ser el resultado de la normativa del siglo XVIII que los regularizaba en $1 / 2$ vara castellana -o vara de Burgos de 0,835905 m- por 1/4 de vara por "4 dedos" de espesor (Schávelzon ,1991). Sin embargo, existe en el Río de la Plata una variabilidad muy grande respecto de las dimensiones las que verán reducido su espesor debido a la deficiente cochura del material en los hornos a leña de la Época Colonial. 
8. En cuanto a la fauna hallada, la mayor parte del conjunto arqueofaunístico analizado por la Dra. Matilde Lanza representa restos de comida descartados en contextos de basura con otros tipos de residuos. Sobre la base de la morfología y las características macroscópicas de las huellas, comparadas con las muestras experimentales realizadas en trabajos anteriores por Lanza (2010; 2011 y 2014), se destacan dos tipos de huellas de corte registradas en los restos de vacuno: a. con un instrumento con un filo similar a un hacha y/o hacha trozadora y b. aquellos cortados con cuchillo. Este tipo de indicios nos estaría indicando que se trata de restos de comida. Muy probablemente el conjunto tenga una cronología que se ubica entre el siglo XVIII y primera mitad del siglo XIX según los datos que aportan los documentos escritos y las investigaciones arqueológicas sobre el procesamiento de los vacunos en la Provincia de Buenos Aires durante el período Colonial y de Independencia Nacional. Teniendo en cuenta el contexto en el cuál fueron encontrados los restos faunísticos fragmentados y fragmentos junto con restos de vidrios, lozas, cerámicas, entre otros hallazgos; y que varios de los restos óseos presentan huellas de corte de procesamiento; la mayor parte del conjunto arqueofaunístico representa restos de comida descartados en contextos de basura con otros tipos de residuos. A partir de la morfología y características macroscópicas de las huellas y comparándolas con las muestras experimentales realizadas en trabajos anteriores (Lanza 2010; 2011 y 2014) se han diferenciado varios tipos de huellas de corte, pero de un tipo específico, registrada en restos de vacunos y/o mamíferos indeterminados grandes. Esto nos permite asociar el conjunto estudiado a un período cronológico determinado. Así tendríamos: a) con un instrumento con un filo similar a un hacha y/o hacha trozadora que nos estaría indicando que se trataría de restos de comida. Muy probablemente este conjunto se puede ubicar entre el siglo XVIII y primera mitad del siglo XIX según los datos que aportan los documentos escritos y las investigaciones arqueológicas sobre el procesamiento de los vacunos en la Provincia de Buenos Aires durante el período Colonial y de Independencia Nacional (Essex Vidal, 1999; Silveira, 1999 y2005 entre otros).

9. La estructura de ladrillos hallada en el último tercio del terreno, que en un primer momento se supuso era un aljibe o una tahona (un molino para obtener harina que se acciona por medio de una rueda de piedra movida con caballos), se trata de una cisterna o tanque enterrado para almacenar agua de lluvia por ejemplo. Los materiales que lo constituyen y el revoque que tiene el interior de sus paredes, sugieren una asignación temporal de la segunda mitad del siglo XIX y primeros años del siglo $\mathrm{XX}$.

\section{Consideraciones finales}

Por todo lo dicho respecto del registro arqueológico obtenido a través de las excavaciones practicadas en el predio de nomenclatura catastral Circunscripción I, Sección A, Manzana 53, Parcela 2, aledaño a la Basílica Nacional "Nuestra Señora de Luján", ciudad de Luján, probable lugar de emplazamiento de la sede original que albergó la Imagen de la Virgen con su cuidador, el comúnmente conocido como "Negrito Manuel", concluimos que:

1. No se han hallado, en forma clara y precisa, restos de las construcciones originales de la Capilla Montalvo fundada en 1685 y que funcionara hasta las primeras décadas del 1700. Esto no indica que no haya estado en el terreno esa estructura sino que hasta ahora no existen indicios claros y firmes de su existencia material en el lugar.

2. Sobre la base del tipo de construcción y los materiales empleados, las estructuras halladas y otros restos constructivos (restos de paredes, patios, veredas, albañales, etc.), corresponden a los siglos XX, XIX y probablemente algo al XVIII, como porciones de los cimientos de la casa lindera en donde se practicaron las trincheras.

3. En cuanto a los artefactos hallados en el registro arqueológico obtenido como resultado de las excavaciones, es importante destacar que corresponden a ocupaciones de los siglos XX, XIX y 

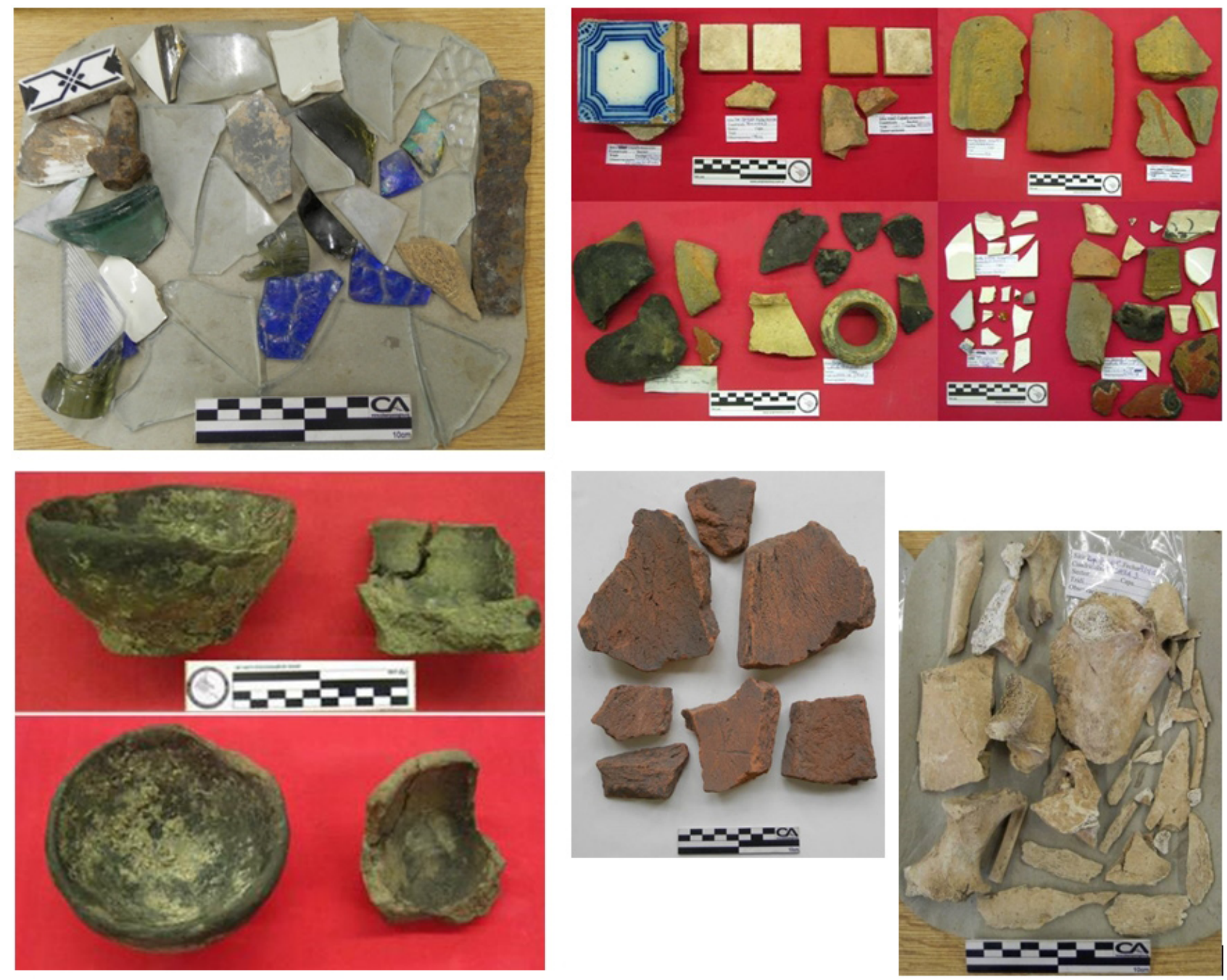

Figura 4. Fragmentos del registro arqueológico recuperado. Se destacan vidrios, fauna y cerámica

XVIII, posiblemente algo al XVII. Es decir, el lugar estuvo ocupado desde Época Colonial y mantuvo una secuencia de ocupaciones humanas desde entonces hasta la actualidad cuando fue demolida, recientemente, la casa de la segunda mitad del siglo XIX.

Perspectivas para un nuevo estudio en el terreno:

Con los estudios llevados a cabo en noviembre de 2015 y mayo de 2016 se ha obtenido un diagnóstico más categórico respecto del objetivo principal de ubicar la Capilla Montalvo. Los restos de esa estructura no se encuentran en el terreno aunque existan hallazgos de Época Colonial. No solo el tipo de hallazgos sino las asociaciones arqueológicas (relaciones de proximidad entre hallazgos) son las que orientaron este tipo de estudios.

Los hallazgos de las fundaciones -base de los cimientos- de la casa vecina hacia el sur, son los que podrían indicar que en el lugar se montó alguna construcción en Época Colonial, quizás la Capilla Montalvo.

Es importante destacar que si bien podrían no hallarse restos de la ocupación de 1685 hasta la primera mitad del siglo XVIII, es relevante el conocimiento que se obtiene con relación a los habitantes de la Época Colonial como aquellos del primer periodo de Independencia nacional.

Desde una perspectiva arqueológica y como posible evaluación final sobre eventuales hallazgos en el terreno, se podrían realizar trincheras exploratorias en el área de acceso por la calle 9 de Julio 
(planchada de concreto) y en cercanía de la pared (montículo de tierra y escombros) que linda con el acceso a la calle San Martín. Con esto no quedarían áreas del terreno sin excavar y sin sondear.

\section{Notas}

${ }^{1}$ Además colaboraron en este artículo: Mariano Darigo, Carolina Leiva, Nicolás Ciarlo, Keila Sulich, Verónica Pernicone, Soledad Pugliese, Yesica Pousa, Augusto López, María Milani, Rocío Rodríguez, Daniel Gómez, Marcelo Gómez, Milva Umaño, Sebastián Presas, Luciana Bauer, Maílin Campos y Carolina Santo

\section{Referencias}

BARRAL, M. E. (2004). Las parroquias rurales de Buenos Aires entre 1730 y 1820. Andes. Antropología e historia. (15). 19-54

BARRAL, M. E. (2013). La Iglesia católica en Iberoamérica: las instituciones locales en una época de cambios (siglo XVIII). Luís Geraldo Silva y Marco Antonio Silveira (Coord. Dossiêr) Dinâmica institucional nas Américas: questões historiográficas (1640-1840). Revista de Historia (169). 145-180.

BINETTI J. (2015 MS). La cruz sin espada. Patrimonio, tradición e historia del Luján temprano, 1671-1742. [2 Parte]. Luján.

CORTABARRÍA, J. (2009). Orígenes de la ciudad de Luján. Luján. Asociación Cultural Ameghino.

DORronZORO, M. (1950). Pago, Villa y Ciudad de Luján. Luján. Edición del autor.

ESSEX VIDAL, E. (1999). Buenos Aires y Montevideo. Buenos Aires: Emecé.

FERNÁNDEZ, M. (1997). El proceso de industrialización de la pampa húmeda: El caso del Partido de Luján (1850-1930). Colección Cuadernos de Trabajo (4).

FOGELMAN, P. (1999). Población de color en una villa en la frontera bonaerense: Luján, 17711815. Signos históricos (23). 9-34.

FOGELMAN, P. (2000). Elite local y participación religiosa en Luján a fines del periodo colonial. La Cofradía de Nuestra señora del Santísimo Rosario. Cuadernos de Historia Regional (20-21). 103124.

FOGELMAN, P. (2002). Reconsideraciones sobre los orígenes del culto a la Virgen de Luján. Entrepasados. Revista de Historia. Año XII (23). 123-148.

FOGELMAN, P. (2006). Simulacros de la Virgen y refracciones del culto mariano en el Rio de la Plata colonial. Farol. 56-67.

HELFER V., PERNICONE, V. y RAMOS, M. (2011). Arqueología de Luján. Las casas de Florentino Ameghino. Tomo I. Buenos Aires: Docuprint.

LANZA, M. (2010). Arqueología experimental: huellas de corte y aserrado. En Bárcena J. y Chiavazza H. (Ed.) Arqueología argentina en el Bicentenario de la Revolución de Mayo. Tomo V. 20272032. 
LANZA, M. (2011). Zooarqueología de sitios históricos, urbanos y rurales, en Buenos Aires. (Tesis de Doctorado). Universidad Nacional de Luján.

LANZA, M. (2014). Arqueología experimental y análisis zooarqueológico de sitios históricos. Teoría y Práctica de la Arqueología Histórica Latinoamericano. Año III, Vol. 3. 163 - 179.

MARQUIEGUI, D. (1990). Estancia y poder político en un partido de la campaña bonaerense: Luján, 1756-1821. Buenos Aires: Biblos.

PRESAS, J. A. (1974). Nuestra Señora en Luján y Sumampa. Estudio crítico-histórico, 1630-1730. Buenos Aires: Ediciones Autores Asociados de Morón.

RAMOS, M. (2000). Algo más que la Arqueología de sitios históricos. Una opinión. En Anuario de la Universidad Internacional SEK. $\mathrm{N}^{\circ}$ 5. 61-75.

RAMOS, M. (2003). El proceso de investigación en la denominada Arqueología Histórica. Actas del Primer Congreso Nacional de Arqueología Histórica. Mendoza. 645-658.

RAMOS, M., HELFER, V., LANZA, M., CUNHA, G., ROMANELLI, A. y TRENCH, N. (2007). Florentino Ameghino: en búsqueda de nuevos registros arqueológicos y documentales. En Néspolo, E. Ramos, M. y Goldwaser B. (Ed.) Signos en el Tiempo y Rastros en la Tierra. II. Sección IV.

RAMOS, M., LANZA, M., HELFER, V., BOGNANNI, F., SENESI, R., HERNÁNDEZ DE LARA, O. y CLAVIJO, J. (2014). Recientes estudios en la "casa de los Ameghino", Luján. Rosario. Anuario de Arqueología (I Congreso Argentino de Arqueología Urbana) Año 6 (6). 83-96.

SALVAIRE, J. (1885). Historia de Nuestra Señora de Luján. Su origen, su santuario, su villa, sus milagros y su culto. Tomos I y II. Buenos Aires: Imprenta Coni.

SCHÁVELZON, D. (1991). Arqueología Histórica de Buenos Aires. La cultura material porteña de los siglos XVIII y XIX. Buenos Aires: Corregidor.

SILVEIRA, M. (1999). Zooarqueología Histórica Urbana: Ciudad de Buenos Aires. (Tesis Doctoral). Facultad de Filosofía y Letras, Universidad de Buenos Aires. MS.

SILVEIRA, M. (2005). Cocina y Comidas en el Río de la Plata. Universidad Nacional del Comahue: EDUCO.

Recibido: $15 / 07 / 2017$

Aceptado: 01/08/2017 